\title{
Analysis of Two New Voltage Level Converters With Various Load Conditions
}

\author{
Mahendranath B and Avireni Srinivasulu, SMIEEE
}

\begin{abstract}
Application of level converter in dual supply voltage circuits is one of the most effective ways to reduce power consumption. To prevent static current, level converter is introduced as an interface at each low-to-high boundary. The design of an efficient level converter with least power consumption and overheads delay is one of the major design constraints. In this paper, two new level converter circuits with low power consumption are proposed for less propagation delay and load adaptability. The proposed level converter circuits are examined using cadence and the design parameters of a $180 \mathrm{~nm}$ CMOS process. The simulation results exhibit that proposed level converters can reduce propagation delay and increase speed over the existing circuits available. These level converters are simulated for different loads and operating conditions. The proposed level converters can operate at different values of $V_{D D L}$ as $+1 \mathrm{~V},+1.8 \mathrm{~V},+2 \mathrm{~V}$ and $\mathrm{V}_{\mathrm{DDH}}$ of +3.3 $V$. The topology reports low sensitivity and has features suitable for VLSI implementation. The proposed circuits are suited for low power design without degrading performance.
\end{abstract}

Keywords- Dual cascade voltage switch logic, level converter, low power, power dissipation, propagation delay

\section{INTRODUCTION}

At present semiconductor device market demands the manufacture of storage devices having higher operating potentiality, and this triggers another surge in the switching speed. The power consumption has become a major issue on portable electronic systems. As a result, the level converter should have enough current to meet the requirements of transmission speed. This leads to considerable current fluctuations during a short time $(\mathrm{d} i / \mathrm{d} t)$, which may raise switching noises on the power supply lines. In case of large capacitive loads, non-negligible voltage bumps are observed on the power supply lines. These are mainly due to the inductive bond wires, package and board traces, which may induce power supply and ground-bounce (switching noise or $L \mathrm{~d} i / \mathrm{d} t$ noise). This noise can also lead to data transition delay, oscillation at the end of signal transitions and crosstalk between adjacent signal lines. Moreover, it can even cause malfunctioning of the circuits that are connected to the

Manuscript received February 28, 2013, revised July 26, 2013

Mahendranath. B is with the Department of Electronics \& Communication Engineering, Vignan University, Vadlamudi, 522213 Guntur, Andhra Pradesh, INDIA.

Avireni Srinivasulu is with the Department of Electronics \& Communication Engineering, Vignan University, Vadlamudi, 522213 Guntur, Andhra Pradesh, INDIA. (Mobile: +91 9502223336; Fax No: +91 863 2534468; e-mail: avireni_s@yahoo.com (or) avireni@ieee.org). same supply lines [1].

Due to quadratic relation between voltage and power consumption, reduction in the supply voltage is very effective in decreasing power consumption. However, that would be at the expense of the circuit delay. In order to lower the supply voltage without the degradation of system performance, Clustered Voltage Scaling (CVS) has been developed in which critical and non-critical paths of the circuit are grouped together [2]. In the CVS Scheme, by using low voltage $\left(V_{\mathrm{DDL}}\right)$ in the non-critical paths and using high supply voltage $\left(V_{\mathrm{DDH}}\right)$ in speed sensitive paths, the whole system of power consumption could be reduced without degrading the performance. Whenever an output from a low $V_{\mathrm{DDL}}$ cluster is to drive an input to a high $V_{\mathrm{DDH}}$ cluster, Level Conversion is required at the interface. The reason being the output from a low swing voltage $\left(V_{\mathrm{DDL}}\right)$ block cannot connect to a PMOS in a high swing voltage $\left(V_{\mathrm{DDH}}\right)$ block directly, since the PMOS cannot shut off with low voltage $V_{\mathrm{DDL}}$. One of the main challenges in the CVS Scheme is to design Level Converters (LCs) with less power and overhead delay to interface low voltage $\left(V_{\mathrm{DDL}}\right)$ blocks with high voltage $\left(V_{\mathrm{DDH}}\right)$ blocks [3].

Despite the fact that level converter also consumes power, any formal technique that attempts to formulate the use of dual supply voltages for circuit design most possibly take the delay of and the power consumed into account. In other words, the level conversion must be accomplished by minimal delay and lower power consumption to achieve high performance CMOS circuits. Furthermore, a structure such as " $V_{\mathrm{DDL}}$ circuit - $V_{\mathrm{DDH}}$ circuit $-V_{\mathrm{DDL}}$ circuit $-V_{\mathrm{DDH}}$ circuit..." need a lot of level converters to be inserted at each " $V_{\text {DDL }}$ circuit - $V_{\text {DDH }}$ circuit" interface [4]. Hence both lowering the power consumed in the level converter and reducing the number of level converters as such becomes an important issue for the use of dual supply voltages. Care has been taken to design level converter accurately for lowering power consumption and propagation delay without degrading performance. In a traditional Dual Cascade Voltage Switching (DCVS), large delay has been resulted because of the contentions problem between different transistors on the level shifting path. This contention problem will lead to increase both in delay time and power consumption [5-13]. For practical purposes, a CMOS logic circuit with mixed gates operating on a lower supply voltage $\mathrm{V}_{\mathrm{DDL}}$ and on a higher supply voltage $\mathrm{V}_{\mathrm{DDH}}$ may be preferred However, any gate operating on $\mathrm{V}_{\mathrm{DDH}}$ and connected after the gate operating on $V_{\mathrm{DDL}}$ generates a short-circuit current. 




Fig. 1 Direct connection of $V_{D D L}$ circuit and the $V_{D D H}$ circuit

Figure.1 shows a CMOS logic circuit taking into consideration the output of first CMOS inverter is directly connected to the second CMOS inverter. The first CMOS inverter operates on lower supply voltage $V_{\mathrm{DDL}}$ and the second one on a higher supply voltage $V_{\mathrm{DDH}}$. If the input node $\mathrm{N}_{1}$ of $V_{\mathrm{DDL}}$ circuit swings from high to low, the output node $\mathrm{N}_{2}$ retains the reverse that is $V_{\mathrm{DDL}}$. Subsequently, the logical high at node $\mathrm{N}_{2}$ should turn off the pull-up transistor $\mathrm{MP}_{1}$ and turn on the pull-down transistor $\mathrm{MN}_{1}$. Although the voltage at node $\mathrm{N}_{2}$ is high enough to activate the NMOS transistor $\mathrm{MN}_{1}$, it cannot turn off the PMOS transistor $\mathrm{MP}_{1}$ due to the fact that $V_{\mathrm{DDL}}<V_{\mathrm{DDH}}-\left|V_{\mathrm{th}, \mathrm{P}}\right|$. Therefore, there exist a static current flowing directly from the applied voltage source to ground through the path of $\mathrm{MP}_{1}$ and $\mathrm{MN}_{1}$. This static current also consumes power which is not desirable for low power application [6]. To restrict this unwanted power consumption, there should be a level converter circuit placed between $V_{\mathrm{DDL}}$ and $V_{\mathrm{DDH}}$ circuits. The main advantage of the level converter circuit is to reduce the static power consumption. Level converter transforms a logical high produced by a $V_{\mathrm{DDL}}$ circuit to the logical high for a $\mathrm{V}_{\mathrm{DDH}}$ circuit. Thus, the condition of both networks $\mathrm{MP}_{1}$ and $\mathrm{MN}_{1}$ are activated at a time as described in Fig. 1 would not be possible, and the power consumption by the static current therefore gets eliminated. In order to achieve high performance CMOS circuits, the level converter circuit must be designed so as to have minimal delay and power consumption.

\section{THE CONVENTIONAL LEVEL CONVERTERS}

The circuit diagram of conventional level converter is shown in Fig. 2. It is termed as Dual Cascade Voltage Switch (DCVS), interposed between gates operating on different supply voltages in a CMOS logic circuit, to prevent the short-circuit current and reduce power consumption. In this circuit there exists two cross coupled PMOS transistors MP and $\mathrm{MP}_{2}$ to generate the circuit load. The cross coupled PMOS transistor acts as a differential pair. As the output at one side gets pulled down, followed by opposite PMOS transistor to turn $\mathrm{ON}$, and the output on that side will be plugged high. Below the PMOS load, there are two NMOS transistors $\mathrm{MN}_{1}$ and $\mathrm{MN}_{2}$ that are regulated by the input signal [7].

Although the level converter blocks the short circuit current, it consumes relatively large dynamic power while carrying out switching operation. If the CMOS logic circuit must have many level converters; the power consumption therefore would have increased to nullify the effort of decreasing the power consumption by using the two supply voltages $V_{\mathrm{DDL}}$ and $V_{\mathrm{DDH}}$. Furthermore, this conventional level converter has relatively large delay as it has to rely on a contention between different transistors on the level conversion [7].

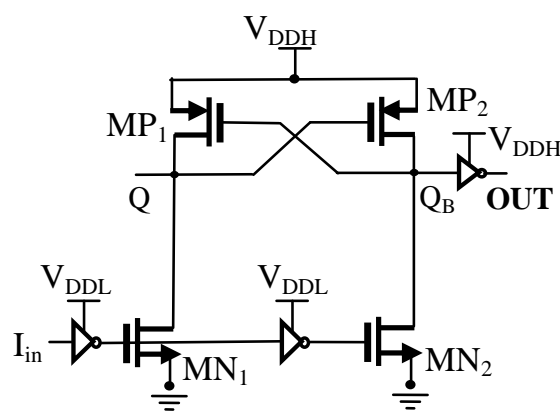

Fig. 2 Conventional level converter (DCVS)

Figure 3 shows the conventional level converter [6], with 12 transistors. This circuit has large power dissipation and propagation delay because it contains more number of transistors.

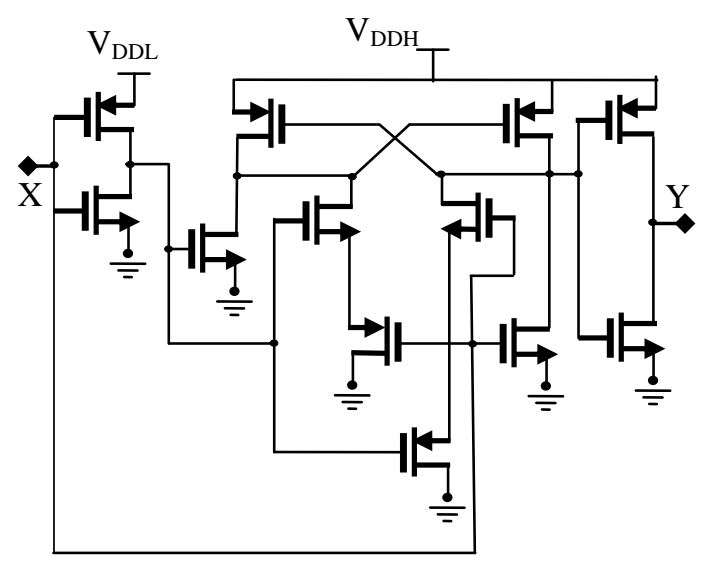

Fig. 3 Conventional level converter [6]

Figure. 4 shows the conventional level converter Standard Dual Cascade Voltage Switch (SDCVS) [7] which endorse the same cross coupled pair of PMOS transistors as DCVS with 14 transistors. The simulation profile of Fig. 4 has indicated the results in the higher propagation delay and power dissipation. To overcome these disadvantages, two new level converters with 10 transistors are proposed in this paper. These proposed circuits reduce the propagation delay and are shown in Fig. 5 and Fig. 6.

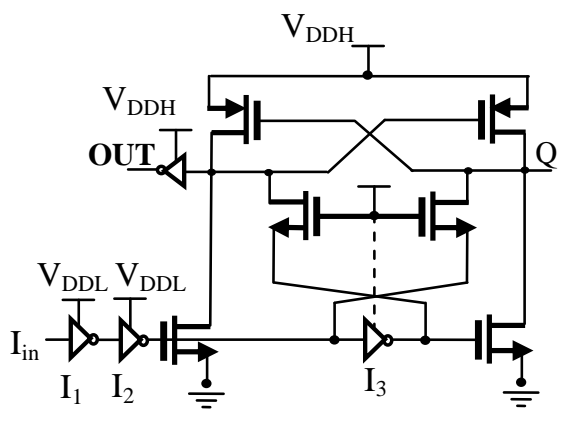

Fig. 4 Conventional level converter SDCVS [7]

The remaining sections of the paper are structured as follows. The new proposed level converter and circuit description is presented in section III. Simulation results and comparative conventional circuits are included in section IV. Finally, conclusion is included in section V. 


\section{PRoposed LeVEl CONVERTERS}

The proposed level converters are shown in Fig. 5 and Fig. 6. In these circuits, the level conversion circuit converts a signal $V_{\text {in }}$ on the lower voltage side to a signal $V_{\text {out }}$ on the higher supply voltage side; the signal $V_{\text {in }}$ is transmitted to the inverted phase, which inturn generated by inverter constituted by transistors $\mathrm{P}_{1}$ and $\mathrm{N}_{1}$, ultimately transmitted to the gates of transistors $\mathrm{N}_{2}$ and $\mathrm{N}_{4}$. The respective gates of transistors $\mathrm{P}_{2}$ and $\mathrm{P}_{3}$ are cross connected to the drains of transistors $\mathrm{P}_{3}$ and $\mathrm{P}_{2}$, while the source of both transistors are connected to the higher supply voltage $\mathrm{V}_{\mathrm{DDH}}$ and $\mathrm{V}_{03}$ is again connected to the gate terminals of $\mathrm{P}_{4}$ and $\mathrm{N}_{4}$ in the output stage, which is further connected to the higher supply voltage $\mathrm{V}_{\mathrm{DDH}}$. Here in this circuit the $V_{\text {in }}$ signal is given as $0 / 1-\mathrm{V}, 0 / 1.8-\mathrm{V}$ and $0 / 2-\mathrm{V}$ voltage levels and $\mathrm{V}_{\mathrm{DDH}}$ is $0 / 3.3-\mathrm{V}$ voltage level.



Fig. 5 Proposed level converter-1

The proposed level converter-1 is shown in Fig. 5, composed of inverter, DCVS logic and an output stage. It converts $0 / 1-\mathrm{V}, 0 / 1.8-\mathrm{V}$ and $0 / 2-\mathrm{V}$ voltage swing to $0 / 3.3-\mathrm{V}$ voltage swing. To reduce the body effect in Fig. 5, the bulk of the PMOS and NMOS transistors are connected to their source and drain terminals respectively. The proposed level converter employs the same cross-coupled pair of PMOS transistors as DCVS. Two NMOS transistors $\mathrm{N}_{5}$ and $\mathrm{N}_{6}$ are added to achieve high speed operation. These two transistors are connected to the gate terminals of $\mathrm{P}_{2}$ and $\mathrm{P}_{3}$ transistors to increase the switching speed of the output transition. In Fig. $5, \mathrm{P}_{1}$ and $\mathrm{N}_{1}$ transistors acts as input inverter with low supply voltage level $\mathrm{V}_{\mathrm{DDL}}$. The output stage consists of PMOS $\mathrm{P}_{4}$ and NMOS $\mathrm{N}_{4}$. The node voltage $\mathrm{V}_{03}$ is connected to the gate terminal of transistor $\mathrm{P}_{4}$ and $\mathrm{N}_{4}$.

The circuit operates as follows: when the voltage level of input signal swings from high to low, the output voltage level of input inverter becomes the lower supply voltage $\mathrm{V}_{\mathrm{DDL}}$. Therefore, $\mathrm{N}_{2}$ and $\mathrm{N}_{5}$ transistors are turned $\mathrm{ON}$; as a result, node $\mathrm{V}_{02}$ is then discharged to ground. Thus, $\mathrm{P}_{3}$ is turned $\mathrm{ON}$ and then voltage level of node $\mathrm{V}_{03}$ becomes a higher supply voltage $\mathrm{V}_{\mathrm{DDH}}$. In this case, $\mathrm{P}_{2}, \mathrm{~N}_{3}$ and $\mathrm{N}_{6}$ transistors are turned OFF, and there by it has been made possible to prevent a short-circuit current from flowing between the higher supply voltage $\mathrm{V}_{\mathrm{DDH}}$ and the ground. When the voltage level of the input signal is switched to logic high, the output voltage level of the input inverter becomes logic low. Therefore, $\mathrm{N}_{3}$ and $\mathrm{N}_{6}$ transistors are turned $\mathrm{ON}$; as a result node $\mathrm{V}_{03}$ is then discharged to ground. In this case, transistor $\mathrm{P}_{2}$ is turned $\mathrm{ON}$ and thereby, transistor $\mathrm{P}_{3}$ turns OFF. There by transistors $\mathrm{N}_{2}$ and $\mathrm{N}_{5}$ are also turned OFF and made it possible to prevent a short-circuit current from flowing between the higher power supply voltage $V_{D D H}$

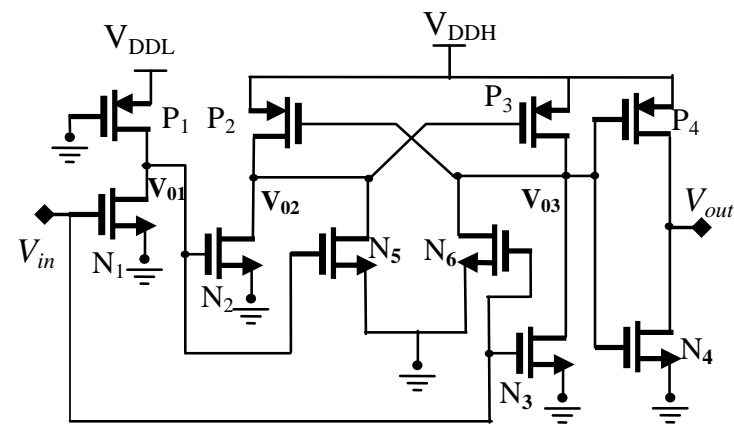

Fig. 6 Proposed level converter-2

and ground. It is thus clear that the output level transition in each input signal condition switches fast. These results contribute to faster output transition as well as contention problem on nodes $\mathrm{V}_{02}$ and $\mathrm{V}_{03}$. As a result of this propagation delay time of the circuit gets reduced.

Figure 6 display the proposed level converter- 2 which is composed of pseudo inverter, DCVS logic and an output stage. It converts $0 / 1-\mathrm{V}, 0 / 1.8-\mathrm{V}$ and $0 / 2-\mathrm{V}$ voltage swing to 0/3.3-V voltage swing. To reduce the body effect in Fig. 6 too the bulk of the PMOS and NMOS transistors are connected to their respective source and drain terminals. The proposed level converter employs the same cross-coupled pair of PMOS transistors as DCVS. Two NMOS transistors $\mathrm{N}_{5}$ and $\mathrm{N}_{6}$ are introduced to achieve high speed operation. These two transistors are connected to the gate terminals of $\mathrm{P}_{2}$ and $\mathrm{P}_{3}$ transistors to increase the switching speed of the output transition. In Fig. 6 , transistor $P_{1}$ and $N_{1}$ transistor acts as input pseudo inverter with low supply voltage level $\mathrm{V}_{\text {DDL }}$. The output stage consists of PMOS $\mathrm{P}_{4}$ and NMOS $\mathrm{N}_{4}$. The node voltage $\mathrm{V}_{03}$ is connected to the gate terminal of transistor $\mathrm{P}_{4}$ and $\mathrm{N}_{4}$.

Nextly, operation of the proposed level converter-2 is explained as follows. While the gate of PMOS $\mathrm{P}_{1}$ transistor is connected to ground it will always be in $\mathrm{ON}$ condition. While the voltage level of input signal swings from low to high, the NMOS transistor $\mathrm{N}_{1}$ turns $\mathrm{ON}$ and the voltage at node $\mathrm{V}_{01}$ is discharged to ground, so that the output voltage level of input inverter becomes low. Therefore, transistor $\mathrm{N}_{3}$ and $\mathrm{N}_{6}$ transistors are turned $\mathrm{ON}$; as a result, node $\mathrm{V}_{02}$ is converted for supply of high voltage $\mathrm{V}_{\mathrm{DDH}}$. Thus, $\mathrm{P}_{2}$ is turned $\mathrm{ON}$ and then voltage level of node $\mathrm{V}_{03}$ becomes a low. In this case, transistors $\mathrm{P}_{3}, \mathrm{~N}_{2}$ and $\mathrm{N}_{5}$ are turned OFF, and there by it is made possible to prevent a short-circuit current from flowing between the higher supply voltage $\mathrm{V}_{\mathrm{DDH}}$ and the ground. When the voltage level of the input signal is switched to logic low, the output voltage level of the input inverter attains lower supply voltage $V_{D D L}$. Therefore, $\mathrm{N}_{2}$ and $\mathrm{N}_{5}$ transistors are turned $\mathrm{ON}$; as a result node $\mathrm{V}_{03}$ then becomes higher supply voltage $\mathrm{V}_{\mathrm{DDH}}$. In this case, transistor $\mathrm{P}_{3}$ is turned $\mathrm{ON}$, and thereby, transistor $\mathrm{P}_{2}$ to OFF. Moreover, transistors $\mathrm{N}_{3}$ and $\mathrm{N}_{6}$ are also turned OFF, and thereby, it is made possible to prevent a short-circuit current from flowing between the higher power supply voltage $V_{\mathrm{DDH}}$ and ground. It is thus clear that the output level transition in each input signal condition switches fast. These results provide faster output transition as well as contention into problems thrusting on nodes $\mathrm{V}_{02}$ and $\mathrm{V}_{03}$. Consequently propagation delay time of the circuit becomes lesser than proposed level converter-1, with no short-circuit current flow; therefore it is possible to reduce the power dissipation. 


\section{Simulation Results}

The circuit in Fig. 5, Fig. 6 and low power level converter [6] and SDCVS [7] were simulated by using cadence and the model parameters of a $180 \mathrm{~nm}$ CMOS process. The simulations were carried out with pulse amplitude of $+1 \mathrm{~V}$, $+1.8 \mathrm{~V},+2 \mathrm{~V}$ and frequency of $1 \mathrm{MHz}$.

In order to observe the performance of the proposed level converters under various load conditions, the conventional and proposed circuits are simulated at load capacitance varying from $1 \mathrm{pF}$ to $15 \mathrm{pF}$ for $+1 \mathrm{~V}$ input voltage and $1 \mathrm{pF}$ to $25 \mathrm{pF}$ for $+1.8 \mathrm{~V}$ input voltage. Standard DCVS level converter in Fig. 2 suffers from the contention problem; therefore simulation results show maximum power and delay over head. On the other hand low power level converter [6] and standard SDCVS [7] level converter uses more transistors in its operation as compared to proposed level converters, that results in increase in power consumption and propagation delay.

The typical simulated input and output waveforms on the configuration of Fig. 5, with $\mathrm{V}_{\mathrm{DDL}}=+1 \mathrm{~V},+1.8 \mathrm{~V},+2 \mathrm{~V}, \mathrm{~V}_{\mathrm{DDH}}$ $=+3.3 \mathrm{~V}$ and output load of $\mathrm{C}_{\mathrm{L}}=10 \mathrm{pF}$ is presented in Fig. 7, 8,10 respectively. It is evident from Fig. 7 simulated input and output waveforms are with amplitude of $+1 \mathrm{~V}$ and $+3.3 \mathrm{~V}$ respectively with no voltage drop. For all the level converters the supply rail $\mathrm{V}_{\mathrm{DDL}}$ of $+1 \mathrm{~V},+1.8 \mathrm{~V},+2 \mathrm{~V}, \mathrm{~V}_{\mathrm{DDH}}$ of $3.3 \mathrm{~V}$ and pulse input parameters shown in Table. I was used.

Figure 9 shows the simulated DC Response of proposed voltage level convrter-1 of Fig. 5. From Fig. 9 it is evident that the output voltage is varied with respect to input voltage.

The layout of the proposed voltage level converter-1 of TABLE I- PULSE INPUT PARAMETERS

\begin{tabular}{|l|l|}
\hline Voltage 1 & $+1 \mathrm{~V},+1.8 \mathrm{~V},+2 \mathrm{~V}$ \\
\hline Voltage 2 & $0 \mathrm{~V}$ \\
\hline Delay Time & $1 \mathrm{ps}$ \\
\hline Rise Time & $2 \mathrm{ps}$ \\
\hline Fall Time & $1 \mathrm{fs}$ \\
\hline
\end{tabular}

TABLE II - ASPECT RATIOS OF FIG. 5 AND 6



Fig. 7 Simulated input and output waveforms of Fig. 5 with load capacitance $C_{L}=5 p F\left(\right.$ Supply rail voltages $V_{D D H}=+3.3 \mathrm{~V}$ and $V_{D D L}=1 V$ ).
Fig. 5 has been designed using Assura layout XL with $180 \mathrm{~nm}$ technology file. Layout of proposed voltage level converter-1 of Fig. 5 is shown in Fig 11. The area of the proposed voltage level converter-1 is $164.64 \mu \mathrm{m}^{2}$.

Fig. 12, 13, 15 shows the simulated waveforms on nodes $\mathrm{V}_{\text {in }}, \mathrm{V}_{01}, \mathrm{~V}_{02}, \mathrm{~V}_{03}$ and $\mathrm{V}_{\text {out }}$ of the proposed level converter-2 with $\mathrm{V}_{\mathrm{DDL}}=+1 \mathrm{~V},+1.8 \mathrm{~V},+2 \mathrm{~V}, \mathrm{~V}_{\mathrm{DDH}}=+3.3 \mathrm{~V}$ and output load of $C_{L}=10 \mathrm{pF}$ respectively. It is evident from Fig. 10 simulated input and output waveforms are with amplitude of $+1 \mathrm{~V}$ and $+3.3 \mathrm{~V}$ respectively without any voltage drop. For all the level converters the supply rail $\mathrm{V}_{\mathrm{DDL}}$ of $+1 \mathrm{~V},+1.8 \mathrm{~V}$, $+2 \mathrm{~V}, \mathrm{~V}_{\mathrm{DDH}}$ of $+3.3 \mathrm{~V}$ and pulse input parameters shown in Table. I was used. The aspect ratios of Fig. 5 and 6 transistors are given in table II.

Figure 14 shows the simulated DC Response of proposed voltage level convrter-2 of Fig. 6. From Fig. 14, it is evident that the output voltage is varied with respect to input voltage.

The layout of the proposed voltage level converter- 2 of Fig. 6 has been designed using Assura layout XL with 180 $\mathrm{nm}$ technology file. Layout of proposed voltage level converter-2 of Fig. 6 is shown in Fig 16. The area of the proposed voltage level converter-1 is $170.79 \mu \mathrm{m}^{2}$.

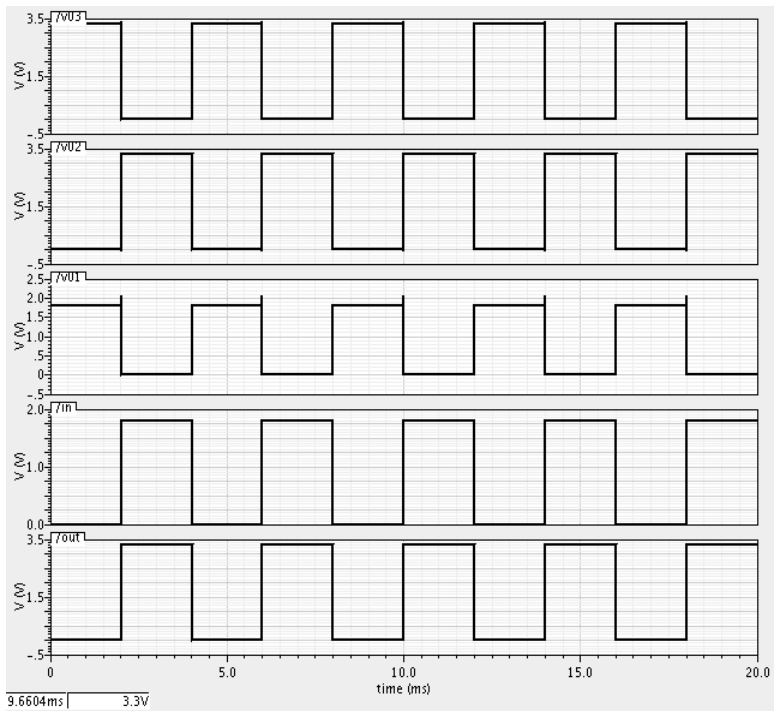

Fig. 8 Simulated input and output waveforms of Fig. 5 with load capacitance $\mathrm{C}_{\mathrm{L}}=10 \mathrm{pF}$ (Supply rail voltages $\mathrm{V}_{\mathrm{DDH}}=3.3 \mathrm{~V}$ and $\mathrm{V}_{\mathrm{DDL}}=1.8 \mathrm{~V}$ ).

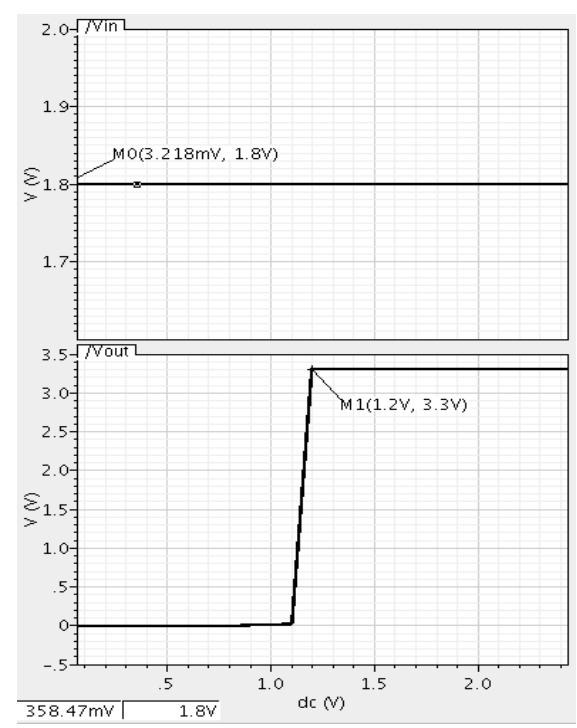

Fig. 9 Simulated DC response of Fig. 5 with load capacitance $C_{L}=10 p F$ (Supply rail voltages $\mathrm{V}_{\mathrm{DDH}}=+3.3 \mathrm{~V}$ and $\mathrm{V}_{\mathrm{DDL}}=+1.8 \mathrm{~V}$ ). 


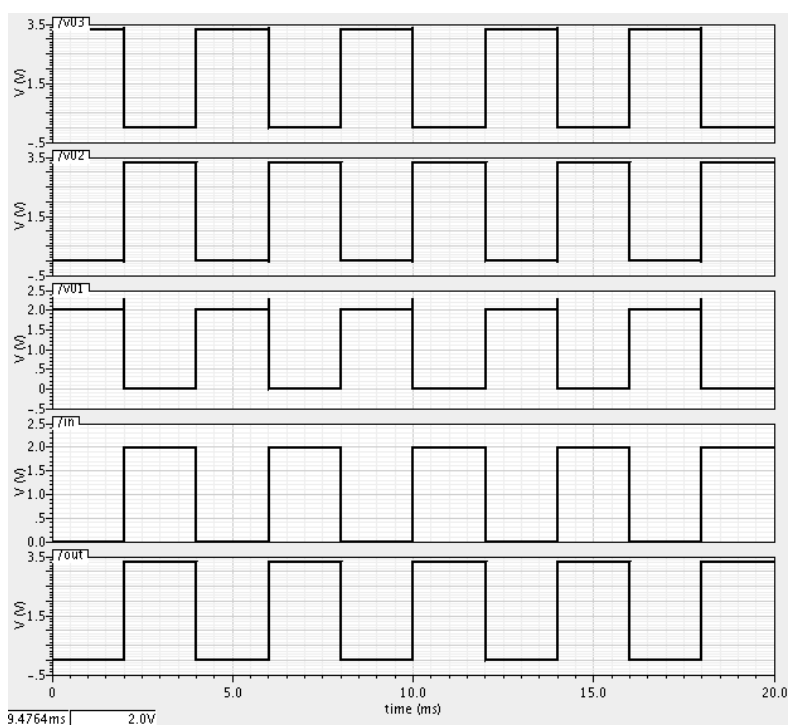

Fig. 10 Simulated input and output waveforms of Fig. 5 with load capacitance $\mathrm{C}_{\mathrm{L}}=20 \mathrm{pF}$ (Supply rail voltages $\mathrm{V}_{\mathrm{DDH}}=3.3 \mathrm{~V}$ and $\mathrm{V}_{\mathrm{DDL}}=2 \mathrm{~V}$ ).



Fig. 11 Layout of proposed Fig 5

Figure 17 empowers the comparison of propagation delay for proposed level converters, low power level converter [6] and conventional SDCVS [7]. In Fig. 17 load capacitance is varied from $1 \mathrm{pF}$ to $25 \mathrm{pF}$ with input pulse amplitude of $+1.8 \mathrm{~V}$ and frequency of $1 \mathrm{MHz}$. It is thus clear that the proposed level converters have less propagation delay and load adaptability than the earlier ones. From the simulation results, it is proved that the delay and power consumption in proposed level converters is very less as compared to that of in the standard DCVS, SDCVS and low power level converters. It is also observed that falling delay and rising delay in case of proposed level converter is much less as compared to the existing circuits. Accordingly, the proposed level converter circuits can be effectively applied to LSI high speed input-output circuit, as an interface between internal and external buses such as a server or exchanger, and as an interface circuit between optical devices for optical communication and an LSI, etc.

Table III represents the comparative study of propagation delay for the proposed level converters, low power level converter [6] and conventional SDCVS [7]. In Table II load capacitance is varied from $1 \mathrm{pF}$ to $15 \mathrm{pF}$ with input pulse amplitude of $+1 \mathrm{~V}$ and frequency of $1 \mathrm{MHz}$. From Table II also it is clear that there is a significant reduction of delay in the proposed level converter compared to the existing circuits.

Table IV shows the simulated values of the propagation delay for the proposed level converter-1 for different supply

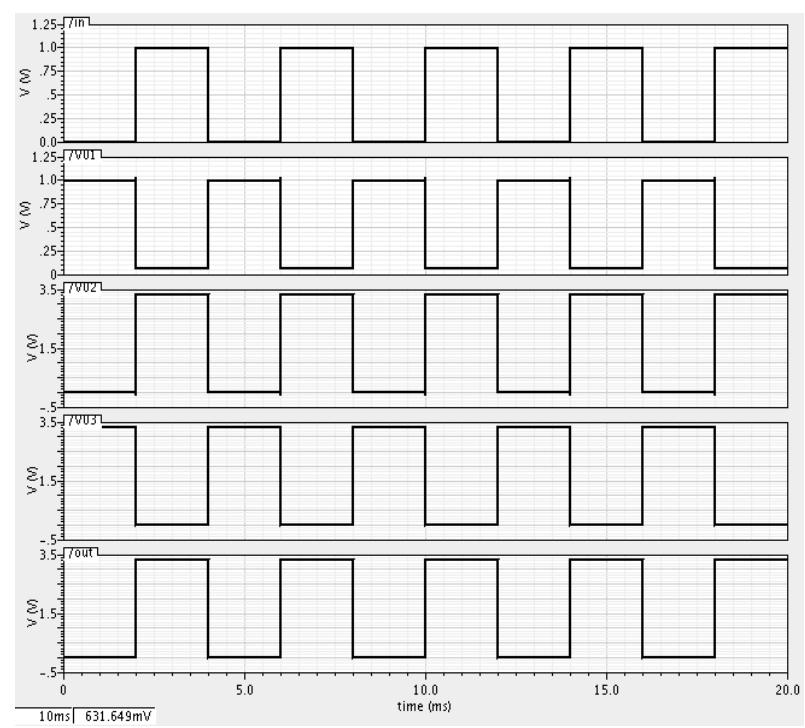

Fig. 12 Simulated input and output waveforms of Fig. 6 with load capacitance $\mathrm{C}_{\mathrm{L}}=5 \mathrm{pF}$ (Supply rail voltages $\mathrm{V}_{\mathrm{DDH}}=+3.3 \mathrm{~V}$ and $\mathrm{V}_{\mathrm{DDL}}=1 \mathrm{~V}$ ).

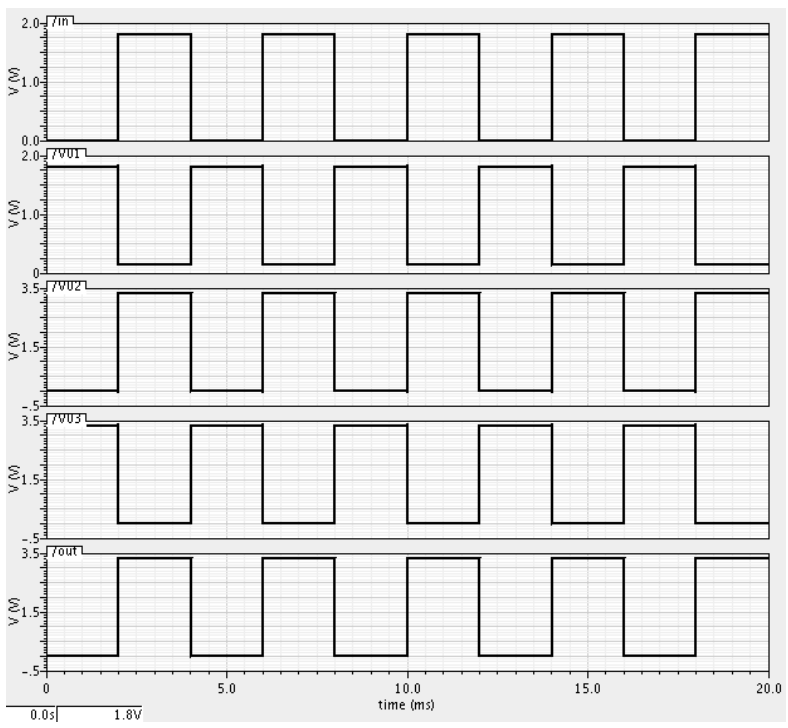

Fig. 13 Simulated input and output waveforms of Fig. 6 with load capacitance $\mathrm{C}_{\mathrm{L}}=5 \mathrm{pF}$ (Supply rail voltages $\mathrm{V}_{\mathrm{DDH}}=3.3 \mathrm{~V}$ and $\mathrm{V}_{\mathrm{DDL}}=1.8 \mathrm{~V}$ ).

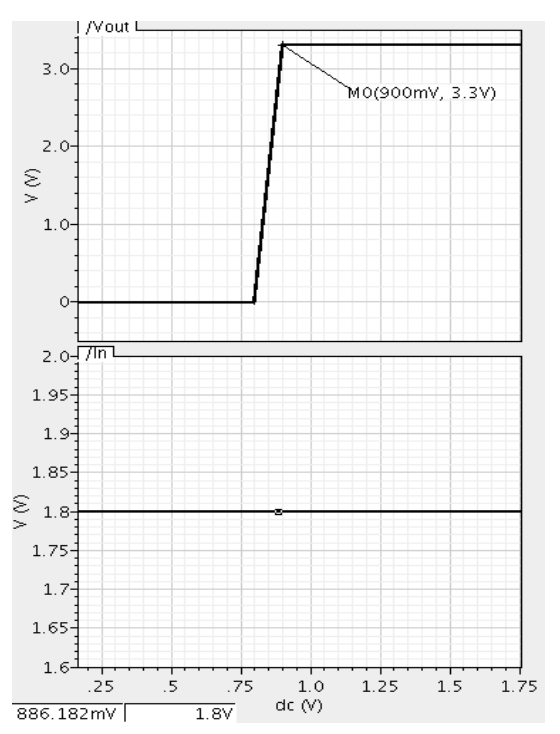

Fig. 14 Simulated DC response of Fig. 6 with load capacitance $C_{L}=10 p F$ (Supply rail voltages $\mathrm{V}_{\mathrm{DDH}}=+3.3 \mathrm{~V}$ and $\mathrm{V}_{\mathrm{DDL}}=+1.8 \mathrm{~V}$ ).

voltages $\mathrm{V}_{\mathrm{DDL}}$ of $(+1 \mathrm{~V},+1.2 \mathrm{~V},+1.8 \mathrm{~V}$, and $+2 \mathrm{~V})$ and $\mathrm{V}_{\mathrm{DDH}}$ of $(+3.3 \mathrm{~V},+5 \mathrm{~V})$ with load capacitor $\mathrm{C}_{\mathrm{L}}$ ranging from 


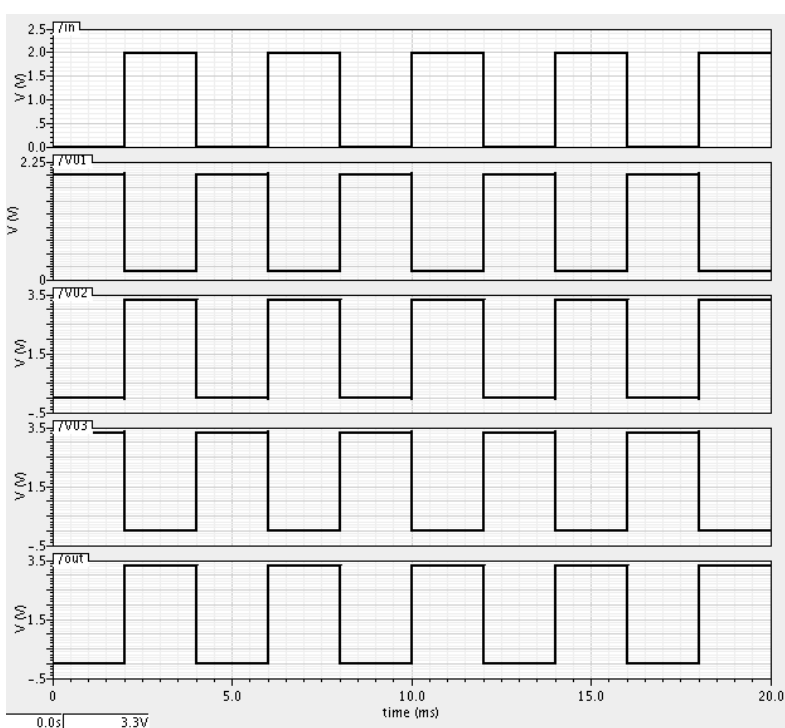

Fig. 15 Simulated input and output waveforms of Fig. 6 with load capacitance $C_{L}=5 \mathrm{pF}$ (supply rail voltages $\mathrm{V}_{\mathrm{DDH}}=+3.3 \mathrm{~V}$ and $\mathrm{V}_{\mathrm{DDL}}=+2 \mathrm{~V}$ ).



Fig. 16 Layout of proposed Fig 6

from $1 \mathrm{pF}$ to $10 \mathrm{pF}$. It is also doubly clear that proposed level converters gives less propagation delay for low voltage and high voltage conversion and hence the proposed converter is very useful for low voltage and high voltage application such as PCI-X Interface.

Table $\mathrm{V}$ shows the simulated values of the propagation delay for the proposed level converter-2 for different supply voltages $\mathrm{V}_{\mathrm{DDL}}$ of $(+1 \mathrm{~V},+1.2 \mathrm{~V},+1.8 \mathrm{~V}$ and $+2 \mathrm{~V})$ and $\mathrm{V}_{\mathrm{DDH}}$ of $(+3.3 \mathrm{~V},+5 \mathrm{~V})$ with load capacitor $\mathrm{C}_{\mathrm{L}}$ ranging from $1 \mathrm{pF}$ to $10 \mathrm{pF}$. It is therefore clear that proposed level converter-2 of Fig. 6 gives less propagation delay for low voltage and high voltage conversion compared to proposed level converter-1 of Fig. 5 and hence the former is stated to have an edge over the later in efficiency and performance as well.

\section{CONCLUSION}

Two new level converters have been tested and designed with $180 \mathrm{~nm}$ CMOS Technology with $V_{\mathrm{DDL}}=+1 \mathrm{~V},+1.8 \mathrm{~V}$, $+2 \mathrm{~V}$ and $V_{\mathrm{DDH}}=3.3 \mathrm{~V}$. It has resulted into minimizing the propagation delay and switching noise. The proposed level converters therefore can reduce the contention problem that existed in the conventional DCVS circuit. Also there is a reduction in the rising time and falling time in the proposed level converters when compared to conventional designs. Simulation results however show that the proposed designs have recorded less noise and less propagation delay, compared to previous designs. The topology reports low sensitivity and has features suitable for VLSI



Fig. 17 Proposed level converters and conventional level converters propagation delay comparison for different loading conditions with $\mathrm{V}_{\mathrm{DDL}}=$ $+1.8 \mathrm{~V}$ and $\mathrm{V}_{\mathrm{DDH}}=+3.3 \mathrm{~V}$.

implementation.

\section{REFERENCES}

[1] Y.Lin, Xuecheng Zou, Zhaoxiao Zheng, W. Huo, Xiaofei Chen and W. Kang, "High-speed, Low Switching Noise and Load Adaptive Output Buffer" in Proc. the Int.Symp. Integrated circuits 2009, (ISCI 2009), Singapore, 14-16 Dec, 2009, pp. 280-282.

[2] M. Hamada, M. Takahashi, H. Arakida, A. Chiba, T. Terazawa, T. Ishikawa, M. Kanazawa, M. Igarashi, K. Usami, and T. Kuroda, "A top-down low power design technique using clustered voltage scaling with variable supply-voltage scheme," in Proc. the IEEE Custom Integrated Circuits Conf., 1998, pp. 495-498.

[3] L. Benini, E. Macii, and G. De Micheli, "Designing low power circuits: Practical recipes," IEEE Circuit Syst. Mag., vol. 1, no. 1, pp. 6-25, 2001.

[4] J. Y. Jou, and D. S. Chou, "Sensitisable-path-oriented clustered voltage scaling technique for low power," in Proc. the IEEE on Comput. Digit. Tech., vol. 145, no. 4, Jul 1998, pp. 301-307.

[5] J. S. Shor, Y. Afek, and E. Engel, "IO buffer for high performance, low-power application," in Proc. the IEEE Custom Integrated Circuits Conf., 1997, pp. 595-598.

[6] Chin Ping-Yuan, Yu Chien-Cheng "A voltage Level Converter Circuit Design with Low Power Consumption" in Proc. the IEEE International Conference on ASIC, Oct. 22-27, 2005, Shanghi, pp. 358-359.

[7] Chien-Cheng Yu, Wei-Ping Wang and Bin-Da Liu "A new level converter for low power applications" in Proc. the IEEE International Symposium on Circuits syst., 2001, vol.1, pp. 113-116.

[8] Mahendranath. B and Avireni Srinivasulu, "Performance analysis of a new CMOS output buffer", in proc. the IEEE International Conference on Circuit, Power and Computing Technologies (IEEE ICCPCT-2013), Kumaracoil, India, Mar 21-22, 2013, pp. 752-755. DOI: 10.1109/ICCPCT.2013.6529041.

[9] T. Venkata Rao and Avireni Srinivasulu, "Modified level restorers using current sink and current source inverter structures for BBL-PT full adder", Radioengineering, vol. 21, no. 4, pp. 1279-1286, Dec 2012. ISSN: 1210-2512.

[10] Shih-Lun Chen, Ming-Dou ker "An Output Buffer for $3.3 \mathrm{~V}$ application in a $0.13 \mu \mathrm{m} \mathrm{1/2.5-V} \mathrm{CMOS} \mathrm{Process"} \mathrm{IEEE} \mathrm{transaction}$ on circuits and systems -II: express briefs, vol. 54, pp. 14-18, Jan 2007.

[11] R. J. Baker, H. W. Li, and D. E. Boyce, "CMOS Circuit Design, Layout, and Simulation”, New York: IEEE Press, 1997.

[12] Avireni Srinivasulu and Madugula Rajesh, "ULPD and CPTL Pull-Up Stages for Differential Cascode Voltage Switch Logic," Journal of Engineering (Hindawi), vol. 2013, Article ID 595296, 5 pages, 2013. DOI: 10.1155/2013/595296 ISSN: 2314-4912. 
[13] I. Kavitha Madhuri, Avireni Srinivasulu, P. Chandra Shaker and Indira Priyadarsini. S, "Two CMOS Schmitt trigger circuits using current sink and pseudo inverters", International Journal of Computer Applications, iC3S - Number 3 , Year of Publication: 2013, pp. 18-21. ISSN: 0975 - 8887.

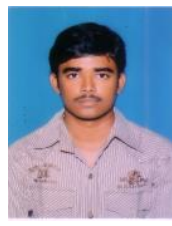

Mahendranath Bheemanboina was born in Tharlupadu, Prakasam District, (A.P), India in 1989. He received the B.Tech degree in electronics and communication engineering from J.N.T.University, Kakinada in 2010 . Currently, he is working towards his M.Tech thesis under the esteemed guidance of Dr. Avireni Srinivasulu. His area of research includes VLSI Design.

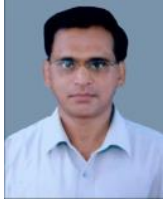

Avireni Srinivasulu was born in Thurimella, Andhra Pradesh, India. He received the B.Tech degree in electronics and communication engineering from Sri Venkateswara University, Tirupati in 1986, M.E, degree in power electronics engineering from Gulbarga University, Gulbarga in 1991, M.S, degree in software systems from Birla Institute of Technology and Science
(BITS), Pilani in 1998 and $\mathrm{Ph} . \mathrm{D}$, degree in electronics and communication engineering (VLSI Design) from Birla Institute of Technology, Mesra, India in 2010 .

He worked as a Lecturer, Assistant Professor, Reader and Associate Professor in the Department of Electronics and Communication Engineering, T.G.L.G. Polytechnic, Adoni; Guru Nanak Dev Polytechnic, Bidar; K.S.R.M. College of Engineering, Kadapa; Defence University Engineering College, Debre-Zeit, Ethiopia; Kigali Institute of Science, Technology \& Management, Kigali, Rwanda; Birla Institute of Technology, Mesra, Ranchi and working as a Professor in the Department of Electronics and Communication Engineering, Vignan University, Vadlamudi, Guntur, India. He has 25 years of teaching and 15 years of research experience in the Department of Electronics and Communication Engineering.

Dr. Avireni.S is a senior member of IEEE, senior member of IACSIT, life member of I.S.T.E and a member of the Institution of Engineers (India). He has published over 30 articles in international journals and international conference proceedings; his main research areas are microelectronics, VLSI design and analog ASIC.

TABLE. III COMPARISON OF PROPAGATION DELAY FOR FIG. 5 FIG. 6 AND CONVENTIONAL LEVEL CONVERTERS FOR DIFFERENT LOAD CONDITIONS

\begin{tabular}{|l|l|l|l|l|l|l|}
\hline \multirow{2}{*}{$\begin{array}{c}\text { Level } \\
\text { Converters }\end{array}$} & \multicolumn{3}{|c|}{$\begin{array}{c}\text { Supply Rail } \\
\text { Voltages }\end{array}$} & \multicolumn{5}{c|}{ Propagation Delay (ns) } \\
\cline { 2 - 7 } & $+\mathrm{V}_{\mathrm{DDL}}$ & $+\mathrm{V}_{\mathrm{DDH}}$ & $\mathrm{C}_{\mathrm{L}}=1 \mathrm{pF}$ & $\mathrm{C}_{\mathrm{L}}=5 \mathrm{pF}$ & $\mathrm{C}_{\mathrm{L}}=10 \mathrm{pF}$ & $\mathrm{C}_{\mathrm{L}}=15 \mathrm{pF}$ \\
\hline SDCVS [7] & $1 \mathrm{~V}$ & $3.3 \mathrm{~V}$ & 4.553 & 9.767 & 15.04 & 19.68 \\
\hline LPLC [6] & $1 \mathrm{~V}$ & $3.3 \mathrm{~V}$ & 4.627 & 8.631 & 14.3 & 15.9 \\
\hline Proposed Fig.5 & $1 \mathrm{~V}$ & $3.3 \mathrm{~V}$ & 4.868 & 8.376 & 13.28 & 16.54 \\
\hline Proposed Fig.6 & $1 \mathrm{~V}$ & $3.3 \mathrm{~V}$ & 2.998 & 7.169 & 12.41 & 15.13 \\
\hline
\end{tabular}

TABLE. IV COMPARISON OF PROPAGATION DELAY FOR FIG. 5 WITH DIFFERENT LOAD CONDITIONS AND SUPPLY RAIL VOLTAGES

\begin{tabular}{|c|c|c|c|c|c|c|c|c|c|c|}
\hline \multicolumn{2}{|c|}{$\begin{array}{l}\text { Supply Rail } \\
\text { Voltages }\end{array}$} & \multicolumn{3}{|c|}{$\begin{array}{l}\text { Capacitor Output load } \\
\left(C_{L}=1 \mathrm{pF}\right)\end{array}$} & \multicolumn{3}{|c|}{$\begin{array}{l}\text { Capacitor Output load } \\
\qquad\left(\mathrm{C}_{\mathrm{L}}=5 \mathrm{pF}\right)\end{array}$} & \multicolumn{3}{|c|}{$\begin{array}{l}\text { Capacitor Output load } \\
\left(C_{L}=10 \mathrm{pF}\right)\end{array}$} \\
\hline $\begin{array}{l}+\mathrm{V}_{\mathrm{DDL}} \\
\text { (Volts) }\end{array}$ & $\begin{array}{l}+\mathrm{V}_{\mathrm{DDH}} \\
\text { (Volts) }\end{array}$ & $\begin{array}{l}\text { Rise Time } \\
\text { (fs) }\end{array}$ & $\begin{array}{l}\text { Fall Time } \\
(\mathrm{ps})\end{array}$ & $\begin{array}{c}\text { Delay } \\
\text { (ns) }\end{array}$ & $\begin{array}{l}\text { Rise Time } \\
\quad(\mathrm{ps})\end{array}$ & $\begin{array}{l}\text { Fall Time } \\
(\mathrm{ns})\end{array}$ & $\begin{array}{c}\text { Delay } \\
\text { (ns) }\end{array}$ & $\begin{array}{l}\text { Rise Time } \\
\text { (ps) }\end{array}$ & $\begin{array}{l}\text { Fall Time } \\
(\mathrm{ns})\end{array}$ & $\begin{array}{c}\text { Delay } \\
\text { (ns) }\end{array}$ \\
\hline 1 & 3.3 & 7.93 & 515.6 & 4.187 & 45.85 & 2.532 & 8.376 & 4.209 & 5.057 & 13.61 \\
\hline 1.2 & 3.3 & 4.44 & 510 & 2.404 & 66.29 & 2.53 & 6.59 & 5.162 & 5.063 & 11.82 \\
\hline 1.8 & 3.3 & 37.54 & 509.3 & 1.462 & 101 & 2.535 & 5.677 & 1.055 & 5.078 & 10.9 \\
\hline 1.2 & 5 & 22.61 & 690.6 & 2.487 & 618 & 3.397 & 7.152 & 1.241 & 6.861 & 13.09 \\
\hline 1.8 & 5 & 55.27 & 683.8 & 1.457 & 936.3 & 3.402 & 6.139 & 498.9 & 6.85 & 11.89 \\
\hline 2 & 5 & 960.8 & 682.9 & 1.546 & 618 & 3.397 & 7.152 & 1.241 & 6.861 & 13.09 \\
\hline
\end{tabular}

TABLE. V COMPARISON OF PROPAGATION DELAY FOR FIG. 6 WITH DIFFERENT LOAD CONDITIONS AND SUPPLY RAIL VOLTAGES

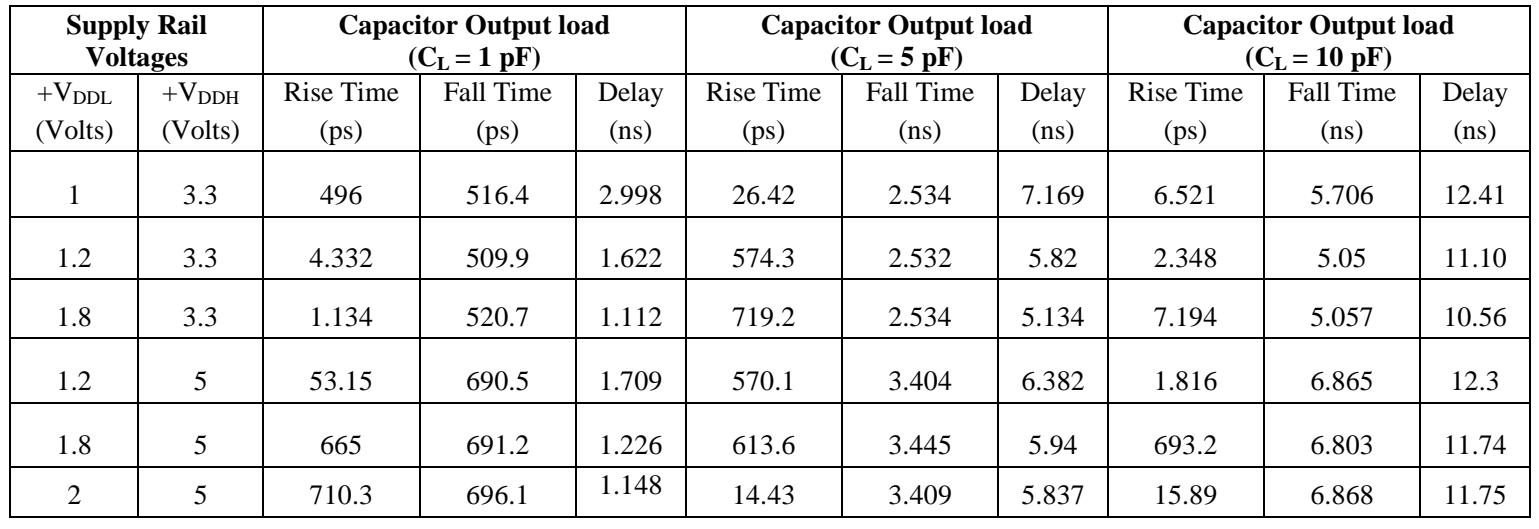

